\title{
Aportes de la psicología al consumerismo: educación y defensa de los consumidores
}

\author{
Nhora Constanza Fuentes \\ José Leonardo Sánchez \\ Andrés M. Pérez-Acosta \\ Universidad del Rosario, Bogotá, Colombia
}

\section{Recibido 15 de junio del 2016 / Aprobado 20 de julio del 2016}

El presente artículo tiene como finalidad determinar los aportes de la psicología al consumerismo. Para este fin, se inició con la contextualización del marco teórico relacionado con el consumerismo, su definición, las circunstancias especificas de la sociedad actual que han favorecido el afianzamiento de esta temática, y los aspectos legales internacionales y nacionales (en Colombia). A continuación, se realizó una revisión de la literatura que señalaba los aportes de la psicología al consumerismo. Finalmente, se planteó una discusión acerca del papel activo que la psicología debe abordar en el tema del consumerismo, los factores psicológicos que intermedian en este proceso, las consecuencias individuales y sociales, así como el nuevo rol que debe enfrentar el psicólogo interesado en la psicología del consumidor.

psicología del consumidor /consumerismo / educación del consumidor / derechos del consumidor

\section{Contributions to the psychology of consumerism: education and consu- mers' defense}

This study aims at determining the contributions of psychology to the phenomenon of consumerism. To this end, we contextualize the theoretical framework, considering current specific societal circumstances, as well as legal aspects both in the international and the Colombian national contexts. A review of the literature allows us to identify specific contributions of the psychology of consumerism. Finally, we discuss the active role psychology should have in this topic, the psychological factors that mediate in the process and the characteristics psychologists interested in the psychology of consumerism should have.

psychology of consumerism / consumerism / consumer education / rights of consumers

Correo electrónico: andres.perez@urosario.edu.co 


\section{¿QUÉ ES CONSUMERISMO?}

Desde hace siglos, han sido los consumidores quienes han establecido la capacidad de elección y compra según sus gustos y preferencias a un productor determinado; del mismo modo, tienen la capacidad de demandar considerando sus propios recursos para adquirir bienes $\mathrm{y}$ servicios. Al contrario, los productores están limitados a ofrecer a sus clientes los bienes y servicios con el firme propósito de satisfacer las necesidades de los mismos (Penz, 1986).

El mercado se ha convertido en una institución central que facilita, de forma eficaz el intercambio de bienes y servicios en las distintas áreas de la vida económica y social de los individuos; es por esto que la relación entre productores y consumidores ha sido un motivo de controversia. Lo anterior hace prever el poder que los consumidores tienen sobre los productores, pues estos deben estar en la capacidad de satisfacer en toda ocasión a su público. Sin embargo, el análisis empírico ha hecho ver que, en el mercado, el poder que debería tener el consumidor no se practica; por el contrario, se refleja una relación asimétrica entre los dos agentes protagónicos. En este sentido, los consumidores, al ser conscientes de esta asimetría relacional, afirman que el poder del mercado se otorga, en gran medida, a los productores y no a los consumidores; por lo anterior, los consumidores hacen notar la necesidad de transformar estas pautas de interacción entre los productores, el Estado y los consumidores con el fin de garantizar la soberanía del consumidor, así como de limitar la soberanía de la que, en la actualidad, goza el productor. En conclusión, lo anteriormente descrito se entiende como consumerismo: "Una demanda dirigida a la modificación de las relaciones de intercambio en el mercado, de forma que dichas relaciones se alejen del principio de soberanía del productor y se acerquen a la soberanía del consumidor" (Ramírez, Navarro, y Trujillo, 2002, p. 146). El consumerismo no solo se refleja en las actitudes y opiniones de la comunidad, también se pueden observar comportamientos específicos, que son el resultado de los nuevos criterios que los ciudadanos están empleando para la adquisición de bienes y servicios.

\section{ACTITUDES Y COMPORTAMIENTOS CONSUMERISTAS}

Álvarez y Álvarez (1988) mencionan una perspectiva diferente del consumerismo. Primero, este no está enmarcado directamente en el rol consumidor, por ejemplo, cuando se hace una compra de un bien o servicio; la problemática también hace referencia a lo que es trascendente dentro de la misma sociedad de consumo, por ejemplo, si un individuo toma la decisión de no salir de su casa porque alrededor encuentra innumerables anuncios publicitarios que resultan pretenciosos para él, o si cada día aparecen en la puerta de la casa varios vendedores ofreciéndole mil y un productos; en estos casos, la persona no necesita realizar directamente una compra pero, de manera indirecta, la sociedad de consumo la está bombardeando con una serie de problemas a los que se 
les debe dar una solución. Segundo, la sociedad de consumo actual involucra la creación de las necesidades en los clientes antes de hallar en sí mismo cuáles son las necesidades básicas y fundamentales que el mercado debe cubrir. Antes se fabricaban productos, bienes y servicios porque era el consumidor quien los demandaba para cubrir sus necesidades, pero, como se ha mencionado anteriormente, ahora esto ha sido sustituido por algo que domina el mercado: se elabora primero un producto para así crear una nueva necesidad en el consumidor $y$, a su vez, el consumidor asume la necesidad del producto. En conclusión, la producción de nuevos mercados está dada para crear una necesidad en el consumidor, de tal forma que la producción de dicho producto pueda ser mantenida y sostenida por el consumidor sobre la base de una de las herramientas más utilizadas y efectivas: la publicidad.

García de la Cruz (1995) hace énfasis en los sujetos intensos, tal referirse a los "procesos que permiten la expresión de los intereses colectivos a través de la queja de uno solo de los afectados" (p. 61); así, el consumerista hace uso de la denuncia, reclamación o protesta para cuestionar la pérdida de su soberanía, y esto se refleja en las acciones que estos hacen para defender su poder natural de consumidor. La persona consumerista tiende a ser intensa, actúa de forma individual para hacer valer los intereses de una comunidad o de un grupo más amplio (consumidores en sí o consumidores afectados por el mismo problema); lo anterior se puede denominar como un nivel elevado de comportamiento consumerista. Así mismo, el consumerismo no depende únicamente de los sujetos intensos, también es primordial que existan vías que permitan a los ciudadanos llegar a la realización de protestas, reclamos y denuncias; en este sentido, los sujetos intensos influencian al Estado y las diferentes instituciones gubernamentales y contribuyen a la formación de asociaciones que defiendan las demandas de los consumidores; un ejemplo de las asociaciones mencionadas anteriormente son las OMIC (Oficinas Municipales de Información al Consumidor), los sistemas de arbitraje y las vías de acciones judiciales, mecanismos que favorecen la participación activa en la defensa de los derechos de los consumidores, y, con ello, ser sujetos intensos.

Sintéticamente, el consumerismo hace referencia a una categoría pública presente en la ciudadanía con el fin de defender los derechos como consumidores. Según esta definición, el consumerismo, las actitudes y los comportamientos deben ser entendidos como un asunto público $\mathrm{y}$, por ello, la presencia de esta faceta en los consumidores está determinada por distintos factores de naturaleza pública.

El consumerismo y sus consecuencias (expansión, intensidad en un contexto) están relacionadas con las diferentes estructuras sociales de los ciudadanos; así, los procesos de desigualdad otorgan una condición diferente a los recursos y oportunidades a quienes puedan formar parte del debate público y trabajar en ellos (Galtung, 1964). 
La cultura política, es decir, las orientaciones afectivas, cognitivas $y$ evaluativas realizadas por los consumidores con respecto al sistema político en sí, a los asuntos políticos en específico, son aspectos por analizar en el ciudadano consumerista (Almond, 1980); continuando con la dimensión cultural, se debe añadir que el consumerismo es un nueva tendencia del sistema actual de valores de los países occidentales (Abramson y Inglehart, 1995).

Ruíz de Maya y Alonso (2001) mencionan uno de los primeros acercamientos consumeristas efectuados en el año 1986 en España. La empresa Tabacalera, tras el ingreso de España a la Unión Europea, perdió por ley uno de sus tres negocios de monopolio: la distribución de tabaco en los estancos; de esta forma, se daba paso a la distribución de nuevos competidores en el mercado español. En el año 1995, el monopolio de tabacos otorgó a McLane (la empresa estadounidense con mayor distribución de tabaco) la primera licencia de venta al por mayor en España, y acabó con el monopolio ostentado por Tabacalera durante diez años. A la par, la conciencia social, que se había instaurado inicialmente en Estados Unidos, estaba recogiendo sus frutos en España, en donde, en 1981, la Unión de Consumidores de este país dio inicio a las primeras acciones cívicas en las que se pedía que, en las cajetillas de cigarrillos, se añadiera información acerca de los efectos nocivos del consumo de tabaco, punto que logró su fin en el año 1982; así fue como se fueron conociendo expresiones como "derechos de los no fumadores" o "fumador pasivo", que son bien reconocidas y juegan un rol de transformaciones políticas y culturales en la sociedad actual.

La Unión Europea, como forma de contribución a la reducción del consumo de tabaco y de prevención en menores, aprobó una serie de parámetros sobre publicidad del tabaco en los estados miembros que se deben adoptar sin excepciones. Así, se prohíbe totalmente la publicidad de tabaco en medios convencionales (prensa, radio y televisión) desde el año 2002; la publicidad indirecta, como en discos o ropa, desde el año 2003; el patrocinio de eventos deportivos y conciertos, a partir del año 2006 (Ruíz de Maya y Alonso, 2001).

Según Del Río (1986), el surgimiento del consumerismo como defensa de los derechos del consumidor trajo consigo consecuencias positivas, como el desarrollo de una legislación que avanza progresivamente hacia aspectos más técnicos, que busca hacerse responsable de los procesos de información y persuasión dados por las pautas comerciales; también involucra la realización de investigaciones que intenten acercarse al efecto que tiene la publicidad en el consumidor y temas como el efecto halo, el desaprendizaje de un consumidor frente a una campaña engañosa; finalmente, ha generado diversos debates acerca de los límites y exigencias frente al contenido informativo de la publicidad como medio para garantizar una elección libre de consumo. 


\section{EdUCACIÓN EN EL CONSUMO RESPONSABLE}

Como bien se ha evidenciado en el recorrido teórico, el consumo de productos y servicios es una acción tan obvia en los diferentes contextos sociales que parece imposible sobrevivir en el mundo sin él; es por esto que, en vez de eludir esta condición, en la actualidad, cada persona puede actuar sobre ella. Así la educación al consumidor contribuye al fortalecimiento de la forma en que los consumidores puedan elegir lo que consumen, prestando atención a unos criterios y no a otros, dando énfasis a actitudes específicas y desechando otras, asumiendo un nuevo estilo de vida que favorezca la preservación de la vida y no perjudique a otros seres humanos, y en donde cada sujeto logre un empoderamiento de los derechos que serán asumidos con responsabilidad ante la sociedad y el medio ambiente (Trímboli, 2004).

Álvarez y Álvarez (1988) realizan una lista de las distintas resoluciones referidas a la protección e información del consumidor:

1. En 1971, el Comité de Ministros del Consejo de Europa aprueba una resolución después de constatar la situación insatisfactoria en la que se halla el consumidor; así, solicita a los estados miembros que tomen medidas en las que retomen la temática consumerista en los centros escolares.

2. En 1973, es adoptada la resolución por parte de la Asamblea del Consejo de Europa que establece como cuatro los derechos fundamentales (derecho a la protección y a la asistencia, derecho a la reparación de daños, derecho a la educación y derecho a la representación y consulta..

3. En 1975, se inicia el primer programa preliminar de la Comunidad Económica Europea (CEE., que crea una política de protección e información del consumidor; se destaca su énfasis en la educación del consumidor.

4. En 1977, en la ciudad de Londres, se inicia la celebración del Congreso acerca de la Educación del Consumidor en la Escuela, que contó con la asistencia de profesionales de la enseñanza, miembros de la administración comunitaria y de las mismas organizaciones de los consumidores, y acogió conclusiones esenciales.

5. En 1978, la CEE pone en funcionamiento una red de veinticinco escuelas piloto repartidas en distintos estados de la comunidad acatando una propuesta del congreso en Londres.

6. En 1980, se ejecuta el segundo programa de CEE en políticas de protección e información para consumidores.

7. En 1983, las Naciones Unidas realizan un plan provisional de protección del consumidor insistiendo en la importancia de brindarle información del consumidor.

8. En 1985, se aceptan unánimemente en la Asamblea General de las Naciones Unidas las directrices para la protección del consumidor. 
Trímboli (2004) sostiene que las primeras organizaciones de consumidores han visto las acciones pedagógicas como una de las herramientas principales para alcanzar sus fines, y surge en Estados Unidos esta perspectiva que, finalmente, fue acogida en Europa, en la que la educación al consumidor hace parte de los programas de niños, jóvenes y adultos.Las frases "educación del consumo" y "educación del consumidor" son usadas sin diferenciación tanto en Europa como en Estados Unidos; al contrario, en América Latina, se usa "educación del consumidor" con mayor frecuencia.

Del Río (1986) indica que es indispensable otorgar enseñanza familiar a los padres que enfatice en competencias que permitan establecer planes de consumo en los cuales se piense menos en las soluciones disponibles para una situación y se pase al anticipo de posibles situaciones de consumo; con ello, se espera que sean los mismos padres quienes propongan educar a los hijos frente al consumo, brindando herramientas que les permitan acercarse a la discusión, información y decisión familiar. El resultado involucra avances progresivos en autonomía y responsabilidad en productos de uso personal que favorezcan el desarrollo de las capacidades del niño, aunque siempre dirigido y razonado por el control de los padres.

\section{Aspectos legales: MARCO INTERNACIONAL}

Estos son algunos derechos del consumidor, según Álvarez y Álvarez (1988):
1) Derecho a la información. El consumidor tiene el derecho a adquirir toda la información que necesite para tomar sus propias decisiones de una manera consciente, y así elegir con conocimiento de causa. Este derecho es fundamental, pues es indispensable que el consumidor cuente con información acertada que lo capacite para actuar de forma libre y responsable, con capacidad para discernir y hallar los aspectos inexactos o engañosos de la publicidad, etiquetas, medios de comunicación y cada aspecto que se relacione con la compra, uso o gozo de los bienes, productos o servicios ofrecidos por el mercado.

2) Derechos a la educación. Este derecho afirma que todos los consumidores deben recibir educación a lo largo de sus vidas para lograr ser un consumidor bien informado, y actuar como tal. La educación al consumidor es entendida como la necesidad de adquirir una serie de conocimientos, destrezas y habilidades esenciales para que cada consumidor sea capaz de gestionar movilizaciones que afecten sus decisiones.

3) Derecho a elegir. Todo consumidor debe acceder a una variada oferta de bienes, productos y servicios con precios competitivos, y en el caso de las compañías de monopolio, estos deben recibir un producto con excelente calidad y a un precio justo. Este derecho afirma que cada consumidor debe tener la capacidad de adquirir bienes, productos y servicios básicos 
que sean indispensables, como la alimentación, asistencia, salud, vivienda, el vestido y transporte; es por ello que el derecho de satisfacer estas necesidades es vital.

4) Derecho a la salud y a la seguridad. El consumidor debe ser protegido contra los mismos productos y/o procesos de los bienes y servicios que puedan afectar de forma directa o indirecta la salud o integridad física, tanto a corto como a largo plazo; en este aspecto, los consumidores deben conocer de antemano los riesgos del uso incorrecto de los productos.

5) Derecho a la reparación de daños. Frente a una reclamación justa hecha por un consumidor, este está en el derecho de obtener una compensación justa; así, el consumidor recibirá una reparación al daño que se le haya causado en casos como falsificación, engaño, fraude, productos de mala calidad, incorrecta presentación de un servicio, entre otras. En este derecho, se incluye el recibir ayuda legal y jurídica para sus reclamaciones.

6) Derecho a la representación y a la consulta. El consumidor tiene el derecho de ser oído en el momento en que este quiera defender sus intereses, así como hacer valer sus derechos frente a los distintos organismos en relación con las políticas que, directa o indirectamente, lo afecten.

7) Derecho al medio ambiente saludable. El consumidor debe estar protegido contra cualquier riesgo o peligro existente en el medio ambiente del cual no tiene control; el consumidor debe gozar de un medio ambiente físico que favorezca su calidad de vida y no conlleve riesgos para su propia salud; también se debe garantizar un medio ambiente óptimo para las generaciones presentes y futuras.

El consumidor debe estar dispuesto a realizar discusiones sobre diferentes asuntos relacionados con la prestación de bienes, productos y servicios que utiliza; así, tendrá que mantener una actitud de alerta y búsqueda de información esencial necesaria para argumentar su posición:

1) Actuar. El consumidor deberá revelar conductas que demuestren su preocupación real frente a su propia conducta como consumidor y al impacto que tiene frente a los demás consumidores, en especial en los grupos de consumidores más desfavorecidos. También puede actuar frente a planteamientos contrarios a los derechos del consumidor.

2) Solidaridad. Se busca el actuar solidario por medio de la organización de grupos que permitan obtener la fuerza necesaria para influir a favor de los propios intereses del consumidor.

3) Conciencia con el medio ambiente. Se debe tomar conciencia de que las decisiones individuales o colectivas que se tomen como consumidor pueden afectar negativamente el medio ambiente. Esta responsabilidad se asume de manera concreta; de ese modo, el consumidor debe tomar una postura sensible con relación a la influencia que su consumo tiene sobre 
el medio ambiente, por ejemplo, la responsabilidad de no desperdiciar recursos naturales escasos, no contaminar el planeta y exigir que no haya producciones que destruyan los distintos ecosistemas.

4) Reclamar. Es obligación del consumidor reclamar y denunciar las situaciones injustas que se generen de forma individual o grupal, garantizando para estas una justa decisión.

Estos deberes se consideran esenciales si se parte de la idea de que los consumidores que interesan a la sociedad consumista son aquellos que actúen de forma irracional, impulsiva, sin criterios y sin capacidad de pensar críticamente; es por ello que todas las técnicas de marketing y los demás mecanismos de mercadeo van dirigidos a impulsar la decisión del consumidor hacia la compra de determinados productos, que son los que están interesados en vender. Lo que vale la pena resaltar es que el consumidor ignora cómo funcionan estos mecanismos utilizados para convencerlo, y ahí radica el éxito de las compañías productoras (Álvarez y Álvarez, 1988).

\section{Marco legal nacional (Colombia)}

El derecho de recibir información es parte fundamental desde la Constitución colombiana de 1991, en la que se establece la libertad de expresión, que cobra cada vez más fuerza por el auge de la tecnología, los medios de comunicación entre consumidores y las redes sociales. En el año 1995, una madre intentó demandar mediante tutela a la Comisión Nacional de Televisión colombiana porque, a su juicio, ciertos programas estaban modificando negativamente la conducta de sus hijos; la tutela no prosperó, pero se hace énfasis en que, en esos tiempos, más o menos hace diez años, no existían métodos claros ni caminos por los cuales los consumidores pudieran comunicar sus incongruencias con los servicios prestados (Suárez, 2001).

Ahora bien, el Gobierno, por medio de la Superintendencia de Industria y Comercio, ha emprendido una campaña eficiente para promover los reclamos que se tienen de acuerdo al servicio recibido por los consumidores. En esta campaña, entra un nuevo concepto a actuar entre esta institución (Superintendencia de Industria y Comercio) y las empresas, 1lamado la abogacía de la competencia; con énfasis, se resume como las actividades realizadas por la autoridad de competencia, relacionadas con la promoción de un entorno competitivo para las actividades económicas a través de distintos mecanismos a los cuales exigir el cumplimiento de la ley, principalmente mediante sus relaciones con otras entidades gubernamentales y mediante el incremento de la conciencia pública sobre los beneficios de la competencia. Así pues, el Estado, desde sus principios, y allí lo relacionamos con el párrafo que menciona la Constitución, tiene la obligación de proteger a los ciudadanos tanto en su calidad de consumidores como de productores y formadores de empresas. Para lo anterior, tiene la facultad de intervenir en la economía, lo que puede hacer mediante la regulación de 
los mercados imperfectos, y lograr que las eficiencias sean transferidas a los consumidores, o mediante la promoción y la competencia. Así pues, la función de la abogacía no solamente afecta a las empresas, sino que protege los intereses de los consumidores garantizando los derechos de los mismos (Restrepo, 2012).

Ahora bien, después de realizar un breve repaso de aquellos avances que se han tenido con relación a la legalización de la defensa del consumidor en el mundo, específicamente en España y en Colombia, es necesario ahondar aún más en el contexto jurídico nacional, en donde hallamos la Ley 1480, expedida como el Estatuto del Consumidor el día 13 de octubre de 2011, y que el presidente de la República Juan Manuel Santos informó que empezaría a regir dentro de seis meses, es decir, el 12 de abril del presente año (Congreso de Colombia, 2011).

En términos generales, dicha ley tiene como finalidad proteger, promover y garantizar la efectividad y el libre ejercicio de los derechos de cada uno de los consumidores. También se busca proteger el respeto a la dignidad y a los intereses económicos que hacen especial referencia a, primero, la protección de los consumidores frente a los riesgos para su salud y seguridad; segundo, el acceso de los consumidores a una información adecuada de acuerdo con los términos de esta ley, que les permita hacer elecciones bien fundadas; tercero, la educación del consumidor; cuarto, la libertad de constituir organizaciones de consumidores y la oportunidad para esas organizaciones de hacer oír sus opiniones en los procesos de adopción de decisiones que las afecten, y quinto, la protección especial a los niños, niñas y adolescentes en su calidad de consumidores, de acuerdo con lo establecido en el Código de la Infancia y la Adolescencia. Para efectos del presente trabajo, la descripción partirá del capítulo dos, artículo tres: derechos y deberes de los consumidores y usuarios de la Ley 1480, descritos por la Confederación Colombiana de Consumidores (2011a). Estos son los siguientes:

1) Derecho a recibir productos de calidad. El consumidor debe recibir el producto de acuerdo con las condiciones que establece la garantía legal, las que se ofrecen y las habituales en el mercado.

2) Derecho a la seguridad e indemnidad. Contempla derecho a que los productos no produzcan daño en condiciones normales de uso, así como a la protección contra las consecuencias nocivas para la salud, la vida o la integridad de los consumidores.

3) Derecho a recibir información. Los consumidores deben obtener información completa, veraz, transparente, oportuna, verificable, comprensible, precisa e idónea en relación con los productos que se ofrezcan o estén en circulación; del mismo modo, se debe informar acerca de los riesgos que puedan derivarse de su consumo o utilización, los mecanismos de protección de sus derechos y las formas de ejercerlos.

4) Derecho a recibir protección contra la publicidad engañosa 
5) Derecho a la reclamación. Los consumidores tienen derecho a reclamar directamente ante el productor, proveedor o prestador, y obtener reparación integral, oportuna y adecuada por todos los daños sufridos; también tendrán derecho a acceder a las autoridades judiciales o administrativas para el mismo propósito en los términos de la presente ley. Las reclamaciones podrán efectuarse personalmente, o mediante representante o apoderado.

6) Protección contractual. Los consumidores tiene derecho a ser protegidos de las cláusulas abusivas en los contratos de adhesión, en los términos de la presente ley.

7) Derecho de elección. Los consumidores podrán elegir libremente los bienes y servicios que requieran.

8) Derecho a la participación. Los consumidores podrán organizarse y asociarse para proteger sus derechos e intereses, podrán elegir a sus representantes, participar y ser oídos por quienes cumplan funciones públicas en el estudio de las decisiones legales y administrativas que les conciernen, así como a obtener respuesta a sus peticiones.

9) Derecho de representación. Los consumidores tienen derecho a movilizarse para que sean representados, para la solución de las reclamaciones sobre consumo de bienes y servicios y las contravenciones a la presente ley, por sus organizaciones o los voceros autorizados por ellas.
10) Derecho a informar. Los consumidores, sus organizaciones y las autoridades públicas deben tener acceso a los medios masivos de comunicación para informar, divulgar y educar sobre el ejercicio de los derechos de los consumidores.

11) Derecho a la educación. Los ciudadanos tienen derecho a ser informados y recibir educación sobre los derechos de los consumidores, las formas de hacer efectivos sus derechos y demás materias relacionadas.

12) Derecho a la igualdad. Los consumidores tienen derecho a ser tratados equitativamente y de manera no discriminatoria.

En cuanto a los deberes, se destacan los siguientes:

1) Los consumidores deberán informarse respecto de la calidad de los productos, así como de las instrucciones que suministre el productor o proveedor en relación con su adecuado uso o consumo, conservación e instalación.

2) Los consumidores deben obrar de buena fe frente a los productores y proveedores, y frente a las autoridades públicas.

3) Los consumidores deben cumplir con las normas sobre reciclaje y disposición de desechos de bienes consumidos.

En Colombia, en el año 1967, fue creada la primera Liga de Consumidores en el departamento del Tolima. La Confederación Colombiana de Consumidores (CCC) se llevó a cabo en el año 1970 y se dice que es la "federación de federaciones" al estar conformada por 
organizacionessindicales, depensionados, padres de familia, amas de casa, profesionales cívicos y comunitarios, y es la organización más representativa de los consumidores colombianos. Con respecto al famoso programa de televisión $E l$ Boletín del Consumidor, sus transmisiones se iniciaron en el mismo año de la fundación de la CCC con el objetivo de orientar a los consumidores y usuarios en la protección de los derechos y en el cumplimiento de los deberes (Confederación Colombiana de Consumidores, 2011a).

La Confederación Colombiana de Consumidores (2011b), en su página oficial, afirma que su objetivo fundamental es agrupar a los consumidores con el propósito de defender sus intereses por sí mismos para, de esta forma, combatir el incremento del costo de vida y promover la productividad; su visión es luchar para garantizar que la relación entre consumidores y proveedores mantenga un equilibrio armónico fundamentado en el respeto mutuo, en el que, finalmente, haya crecimiento en el mercado que, con su actividad y desarrollo, beneficie a la comunidad. Para terminar, la misión de la Confederación Colombiana de Consumidores busca apoyar la creación y el fortalecimiento de las organizaciones y ligas; garantizar el respeto de los derechos de los consumidores a la representación, a la protección, a la educación, a informar y ser informados en cumplimiento de la directriz aprobada por la ONU y suscrita por Colombia (Resolución 39/248 de la Asamblea General del 9 de abril de 1985), a la indemnización, a la libre elección de bienes y servicios, y a ser oídos por los poderes públicos. Con el propósito de alcanzar estos objetivos, la CCC realizará todos los esfuerzos necesarios para resguardar los espacios consagrados en la Constitución y la ley en pro de la defensa de los consumidores y usuarios de bienes y servicios.

\section{APORTES DE LA PSICOLOGÍA}

\section{A LA EDUCACIÓN DEL CONSUMIDOR}

Para promover la educación del consumidor, se propone un modelo psicoeconómico que integra variables psicológicas y económicas. Se postula que los individuos con mayores ingresos y menor estado de endeudamiento contarán con una percepción subjetiva de su situación financiera más optimista, lo que conducirá a tener hábitos y conductas de consumo más flexibles. Estas tendencias hacia el consumo reflexivo están asociadas a un mayor bienestar subjetivo y, a su vez, en un estado menor de endeudamiento, a una actitud más austera, y generan así un consumidor eficiente y responsable (Rodríguez, 2005).

El modelo de integración sobre la conducta económica de Fred van Raaij propone que el bienestar subjetivo tiene impacto sobre el ambiente económico percibido, puesto que la experiencia de satisfacción o insatisfacción con el desempeño de los bienes y servicios afecta las percepciones de los consumidores sobre su entorno económico. Así, el bienestar subjetivo es consecuencia de la conducta económica, que puede ser satisfactoria o insatisfactoriamente asociada a la compra o sus reclamaciones (Van Raaij, 1981). 
Por otro lado, están los individuos con menores ingresos y un menor estado de endeudamiento; contarán con una percepción más pesimista de la situación financiera, lo que se relaciona con conductas y hábitos más impulsivos de consumo. Esto se relaciona con un menor bienestar subjetivo, lo que conlleva un mayor estado de endeudamiento; también tenderá a una inclinación hacia el endeudamiento, que conduce a una percepción pesimista de sus finanzas y se engloba en un consumidor irresponsable e impulsivo (Rodríguez, 2005).

En el modelo simbólico-cultural del comportamiento, se considera una congruencia entre el autoconcepto, la imagen y el comportamiento del consumidor. $\mathrm{Su}$ enfoque principal consiste en la relación del autoconcepto con el consumidor. Se precisaron nueve dimensiones: (1) ser real, cómo una persona se percibe a sí misma; (2) ser ideal, cómo a una persona le gustaría percibirse a sí misma; (3) ser social, cómo cree una persona que otros la perciben; (4) ser social ideal, cómo la persona quisiera que los otros la vieran; (5) ser esperado, cómo una persona quisiera actuar; (6) ser situacional, cómo una persona quisiera actuar en diversos contextos; ser extendido, el impacto de las posesiones en la autoimagen; (8) seres posibles, lo que una persona percibe que le gustaría llegar a ser o teme llegar a ser; y (9) ser afiliado, manifiesto en la forma como las personas se definen a sí mismas en términos de otros o de grupos a los cuales están afiliados. Así pues, el consumidor tiende a seleccionar productos y tiendas que guardan relación con su autoconcepto (Onkvisit y Shaw, 1987).
Por otro lado, Del Río (1986) afirma que el sistema más influyente encargado de dar cuenta de las capacidades, peculiaridades y dimensiones de una persona es la familia; en este sentido, la educación debe enfocarse, en buena parte, en un marco familiar, antes de que el niño inicie su aproximación al contexto social.

Davis (1976) indica que la familia es, en sí, quien representa la unidad auténtica de consumo, encargada de reproducir nuevos consumidores tanto en aspectos físicos como en los culturales. Continuando con Del Río (1986), hay que señalar que la educación de consumo en el niño es fácil si se produce desde el ámbito familiar, pues este es natural y explícito; es por ello que cualquier programa de educación de consumo debe implicar uno de educación de la familia, y de educación para el niño realizada por la propia familia.

Thompson y Tuden (1959) plantearon tempranamente dos tipos básicos de decisión de consumo referentes al hogar. El primero hace referencia a una estrategia de resolución de problemas cuyo objetivo principal es el uso del consenso, que es adquirido por medio de una consonancia entre las preferencias y prioridades que, generalmente, dejan a todos satisfechos; este se caracteriza por ser un método educativo, que genera mayor coherencia, equilibrio en el presupuesto familiar y en los hábitos de consumo, aspecto que puede ser inculcado en el niño desde un inicio y le permite asumir una práctica por medio del aprendizaje de roles y modelos de resolución de conflictos. El segundo tipo de estrategias de decisión son las acomodativas; 
estas no recurren al razonamiento y no están dirigidas a la búsqueda de información, por lo que se dice que hay un acercamiento a las resoluciones más que a las soluciones, y, en este sentido, el nivel educativo del consumidor es inferior al mencionado inicialmente.

La conclusión a la que se ha llegado es que son pocos los padres que educan a sus hijos en temas de consumos y compras; a su vez, en el ámbito familiar, los hábitos de discusión y análisis de problemáticas de consumo no son características recurrentes, esto casi siempre reforzado por las diferentes circunstancias ambientales que no favorecen la apertura de espacios de reflexión, como lo es la incompatibilidad de horarios o estímulos adversos como la televisión (Del Río, 1986).

Hay que señalar que la influencia paterna recibida por el niño no solo es dada por la publicidad o los hábitos de familia, sino que también determina el momento final de la compra en sí. Tal como afirman Ward, Klees y Robertson (1987), hay un proceso del niño que se caracteriza por la adquisición de destrezas, conocimientos y actitudes (consumer socialization). Es indispensable para que este actúe como un consumidor dentro del mercado, y esto es posible, según el modelo de aprendizaje social de Bandura, por la observación del modelo de los padres en el lugar de venta o en la televisión; como bien es entendido, pocos padres utilizan los propios espacios de mercado para educar a los jóvenes, y especialmente a los niños, quienes suelen ser más influenciables y actuarán, finalmente, frente a los padres en el lugar de compra.
Otro aporte de la psicología a la educación del consumidor se encuentra en el estudio del concepto de actitud como variable que permite otorgar al consumidor estrategias para un consumo responsable. La actitud es un concepto que pertenece a la psicología social y de la personalidad, y está vinculada con las diferentes interrelaciones que se originan frente a creencias y sentimientos favorables o desfavorables otorgados a un objeto social que goza de significado. De esta inter-relación, se espera como resultado comportamental una conducta coherente entre ambas variables; sin embargo, esto no debe simbolizar una regla, pues en ocasiones las actitudes representan ambivalencia (Baron y Byrne, 2005).

Dado que los sentimientos y las creencias, en ocasiones, no logran ser importantes predictores de una conducta, se genera la necesidad de realizar una nueva búsqueda en estrategias de intervención ,y surgen nuevas inquietudes en la esfera de la investigación. Es en este sentido que la comprensión de las actitudes es necesaria para ahondar en temas del uso racional de los recursos o en temas generales de consumo, en los que la certeza de sentimientos y creencias no siempre garantiza una conducta esperada, y da paso a atribuciones causales enmarcadas en pensamientos más fuertes que eluden el compromiso hacia el cuidado por el entorno como una responsabilidad de otros (Navarro, 2016).

Como afirma Navarro (2016), es primordial que se continúe realizando acercamientos a la comprensión de 
la realidad de los diferentes contextos culturales, para así construir una mejor unidad entre las percepciones y actitudes frente a temas relacionados con la vida cotidiana.

En este sentido, educar desde las actitudes a los consumidores podría ser uno de los caminos donde la psicología proponga nuevas formas de acercamiento al tema del consumerismo, en donde el deseo de consumo responsable se instaure eficazmente y favorezca creencias y emociones coherentes con la conducta que se espera.

\section{Aportes de LA PSICOLOGía A LA DEFENSA DEL CONSUMIDOR}

En la defensa del consumidor, varios gobiernos nacionales han creado una serie de instituciones reguladoras que intentan establecer los mejores precios en el mercado para no afectar los derechos de los consumidores. En el caso de la regulación de las empresas de telecomunicaciones que en este momento están en auge, ya que prestan un servicio que se volvió indispensable para los consumidores, y es el de telefonía celular e Internet, es un campo de consumo que recibe más de la mitad de quejas al año ante la Superintendencia de Sociedades. Así mismo, las entidades de defensa del consumidor, tanto públicas como privadas, han presionado a las empresas de telecomunicaciones y a las concesionarias de energía eléctrica para que mejoren la atención. También se ha hecho una revisión por América Latina, donde existen datos de que no solamente en Colombia las empresas de telecomunicaciones lideran los rankings de reclamos de los consumidores divulgados por las entidades de protección y defensa de los consumidores (Dolci, 2007).

Es decir, el comercio electrónico, como también afirman Cubillos y Rincón (2002), comprende no solo las ventas o adquisiciones que el empresario y el usuario realizarán a través de una red de comunicaciones, como Internet, sino que abarca todas las etapas del negocio empresarial, siempre que estas se realicen a través de la red. Así, se puede incluir, entre otras, las siguientes actividades que tienden a incidir, necesariamente, en los comportamientos que desarrollan los consumidores o las personas que acceden a bienes y servicios finales:

- la apertura de una empresa o establecimiento virtual;

- la oferta de productos o servicios;

- la publicidad de productos y servicios dentro de la red;

- el intercambio de la información entre el vendedor y el posible cliente;

- los mensajes de datos transmitidos;

- los pagos online o por medios electrónicos;

- la distribución y entrega de los productos y servicios adquiridos por los consumidores; los servicios pre y postventa.

Normalmente, la comunicación entre el vendedor y el consumidor se hace mediante mensajes electrónicos que se envían a través de una pantalla de registro; por ello, los datos con los que cuenta el proveedor, incluida la dirección electrónica 
del usuario, garantizan que la propaganda electrónica y la nueva oferta de productos y servicios permitan desarrollar un hostigamiento publicitario, por cuanto el carácter personal del comercio electrónico garantiza que el mensaje enviado sea leído por el receptor del usuario. Así también, está la responsabilidad por los productos en razón a las marcas como propaganda comercial, pues este punto es de gran relevancia para el desarrollo normal y seguro de la actividad económica. De esto se deriva que la información suministrada deba ser veraz y suficiente para que el consumidor pueda escoger; es importante inculcar que la propaganda efectuada a través de imágenes deba corresponder, como mínimo, a la realidad de los productos; con el objeto de lograr esta garantía, algunos proveedores colocan en sus portales videos o secuencias de imágenes de su producto a fin de que el consumidor pueda apreciarlo mejor (Rodríguez, 2005).

Considerando los nuevos contextos que se están creando para realizar transacciones de comercio, se ha realizado un estudio en el que se detalla un perfil del consumidor para propiciar las actividades comerciales electrónicas o virtuales; cada vez son más los espacios y las empresas que quieren ingresar a este medio. Es por esto que, por medio del estudio, se pretende considerar qué precauciones se deben tener al realizar una transacción por internet y qué aspectos psicosociales tener en cuenta en relación con el consumidor. Para detallar el tema, se define la desconfianza del consumidor hacia la venta tradicional como el grado en que este cree, de forma general, que los vendedores manipulan la información sobre sus productos con el objeto de conseguir la venta; ahora entendemos la desconfianza hacia la venta por medios virtuales como el grado en el que el consumidor cree que el conjunto de las empresas de Internet usa técnicas engañosas o manipuladoras para conseguir la venta de sus productos. Algunos aspectos importantes que influyen son el nivel de educación de los individuos; se ha encontrado que, a mayor nivel de educación, mayor es la tendencia a percibir algún tipo de engaño por técnicas publicitarias manipulativas (Yang, Chandlrees, Lin, y Chao, 2009).

Así también, se encontró que la desconfianza está directamente relacionada con la aversión general al riesgo; en la revisión, se encuentran dos componentes: la incertidumbre percibida en los resultados de una determinada decisión o elección, y la importancia percibida de las consecuencias negativas asociadas a los resultados de dicha elección. También se evalúa cómo la cantidad o el precio de la compra influye directamente sobre estas dimensiones; no será lo mismo comprar un automóvil que un juguete. Así mismo, la aversión general al riesgo es un rasgo personal que difiere de unos individuos a otros, y que se manifiesta como una predisposición a responder de forma negativa ante las situaciones de incertidumbre (Mandrick y Bao, 2005). Esto se traduce en que consumidores con actitudes negativas al riesgo tenderán a percibir mayores riesgos relacionados a cualquier transacción o compra virtual en comparación con aquellos con menor percepción de riesgo (Pascual y Román, 2011). 
Lo anteriormente mencionado revela que, si bien desde la parte jurídica han existido avances y estrategias de defensa del consumidor, la psicología no parece haber dado grandes pasos hacia esta en aspectos tales como la misma investigación del tema del consumerismo.

Bien se sabe que el consumerismo ha surgido como resultado del mundo industrializado y el deseo del cliente de hacer valer sus derechos como consumidor, así como de la iniciativa por parte de las empresas de generar estrategias de defensa para el usuario que permitan un equilibrio en la relación consumidor-empresa. En esta medida, los cambios estratégicos deben estar enmarcados en el abandono de la apreciación de que los clientes son solo una masa abstracta que compra un producto o servicio; al contrario, debe haber una transformación en la percepción de los clientes, en la que estos sean entendidos como un conjunto de individuos organizados, enteramente identificables y diferenciables, para con ello lograr establecer una relación frente a frente en la que se construyan soluciones particulares para cada consumidor (Ramírez, 2005).

Un ejemplo claro de los aportes de la psicología al consumerismo lo encontramos en un estudio que se llevó a cabo en Barranquilla, Colombia, en donde se quiso evaluar la calidad en el servicio que brindan los centros de atención a usuarios por medio de una estrategia organizacional denominada "Cliente Incógnito"; el estudio se desarrolló dentro del marco teórico de la psicología organizacional. Como bien lo han señalado Botero y Peña
(2006), la comprensión del tema de servicio al cliente representa hoy en día una práctica fundamentalmente inevitable, y es, pues, un proceso justo y necesario.

En la actualidad, las grandes organizaciones, ya sean de naturaleza pública o privada, están dando paso a satisfacer enteramente a sus clientes, pues reconocen que de ello depende su éxito como organización (Wellington, 1997), y han convertido "el servicio al cliente" en una importante estrategia de mercado que favorece su supervivencia en el mismo (Serna, 1999).

El consumerismo es el resultado de las inconformidades de los usuarios con los productos y servicios ofrecidos por las organizaciones; sin embargo, todas estas insatisfacciones y requerimientos deben ser atendidos y tomados en cuenta, ya que son los consumidores la razón de ser de cualquier negocio. Así pues, es vital que las organizaciones creen en los consumidores una percepción positiva sobre el producto y servicio que se ofrece, y así satisfacer sus necesidades e intereses (Ruiz-Olalla, 2001), pues de ello dependerán las mismas intenciones de compra (Cronin y Taylor, 1992).

Desafortunadamente, la idea de resaltar al cliente como un agente protagónico en la sociedad de mercado en varias ocasiones no quiere decir que así sea; es decir, es cotidiano escuchar frases como "el cliente siempre tiene la razón" o "los clientes son primero". Sin embargo, no es un secreto para nadie que, en la sociedad de consumo, abundan los clientes descontentos (Botero y Peña, 2006), y allí 
aparece el consumerismo: un deseo de colmar necesidades insatisfechas.

Surge entonces el servicio al cliente, entendido como "un conjunto de estrategias que una compañía diseña para satisfacer, mejor que sus competidores, las necesidades y expectativas de sus clientes externos", y por ello puede ser entendida, a su vez, como una estrategia que busca la defensa de los derechos de los usuarios (Serna, 1999, p. 17).

Finalmente, Botero y Peña (2006) hacen referencia al término de cultura organizacional, entendido como "conjunto de elementos interactivos fundamentales, compartidos grupalmente, acumulados a lo largo de la vida de la empresa a la cual identifican, por lo que son transmitidos a los nuevos miembros, y que son eficaces en la resolución de los problemas" (p. 221). Este término es fundamental, dado que tiene el propósito de indicar que toda organización debe tener una actitud referida al servicio al cliente que debe ser percibida a través de la propia cultura organizacional.

\section{CONCLUSIONES}

Cualquier persona podría afirmar que es inevitable esquivar la sociedad actual de consumo. Día tras día, las diferentes organizaciones han creado innumerables productos que se han convertido en necesidades para los consumidores, y esto, a su vez, ha traído consigo variados reclamos referidos a la calidad del producto.

En este sentido, la legislación nacional e internacional ha tenido un enorme desarrollo en el ámbito de protección del consumidor y ha constituido una herramienta de suma importancia que permite y favorece la efectiva participación de los usuarios dentro del sistema de consumo.

Ahora bien, en la aproximación de la psicología del consumidor referida a la educación y defensa del mismo, los aportes existen; sin embargo, estos han sido incipientes, de tal manera que no han permitido el acercamiento por parte de los usuarios, de forma directa, a los temas anteriormente nombrados.

Por otro lado, los aportes de la psicología a la educación del consumidor han representado un avance referido específicamente al contexto familiar, en el cual la educación debe iniciarse desde la niñez, donde los padres juegan un papel primordial en la enseñanza de nuevos modos de relación entre la sociedad de consumo y el consumidor. Es, pues, la familia el contexto principal en el cual se debe inculcar, desde tempranas edades, la adquisición de repertorios conductuales que favorezcan el consumo responsable y razonable.

Continuando con los aportes que la psicología ha realizado al consumerismo, debemos señalar que, si bien en la educación han sido notables dichos aportes, en el contexto de la defensa del consumidor, estos tienden a ser implícitos, debido a que los estudios e investigaciones respecto al mismo no se han desarrollado de manera explícita y, en consecuencia, el acercamiento al contexto psicológico de la defensa de los consumidores parece representar un trabajo de revisión literaria arduo, que requiere de una inversión de 
tiempo extenso que permita un análisis completo y exhaustivo.

En el presente artículo, se consideran fundamentales las investigaciones dentro de la psicología del consumerismo, aquellas que han estudiado temas como las actitudes (referidas al tema de psicología social y de la personalidad), la cultura organizacional (psicología organizacional), aprendizaje (psicología básica y del desarrollo); sin embargo, concluimos que se debe iniciar un proceso en el que este tema sea trabajado y estudiado como una temática trasversal de la psicología del consumidor.

A partir de todas las aproximaciones a los aspectos psicosociales que intervienen en el consumidor, se hace un llamado a una publicidad objetiva, con trasparencia de todas las cualidades del producto; también se refieren todos los derechos que tienen los individuos como consumidores y una proclamación para hacerlos cumplir. Más allá de un mercado en el cual se beneficie a las empresas, el mercado debe estar dirigido a beneficiar a los consumidores y respetar sus derechos, ya que desde la misma Constitución se hacen explícitos.

\section{ReferenCIAS}

Abramson, P., y Inglehart, R. (1995). Value Change in Global Perspective. Ann Arbor: University of Michigan Press.

Almond, G. (1980). The Intellectual History of the Civic Culture Concept. En G. Almond, y S. Verba (Eds.), The Civic Culture Revised. Londres: Sage.
Álvarez, L., y Álvarez, M. (1988). El consumo va a la escuela. Barcelona: Laia.

Baron, R., y Byrne, D. (2005). Psicología Social. Madrid: Pearson.

Botero, M., y Peña, P. (2006). Calidad en el servicio: el cliente incógnito. Suma Psicológica, 13(2), 217-228.

Congreso de Colombia. (2011). Estatuto del consumidor: Ley 1480. Recuperado de http://www.comunidadcontable. com/BancoMedios/Documentos\%20 PDF/ley\%2014802011.pdf

Confederación Colombiana de Consumidores. (2011a). Estatuto del consumidor: Ley 1480. Recuperado de http://consumidores.org.co/index. php?option $=$ com_content $\&$ view $=$ article\&id=124:1ey-1480-de2011octubre-12\&catid=19:legislacion \&Itemid $=126$

Confederación Colombiana de Consumidores (2011b). Quiénes somos: historia. Recuperado de http:// www.ccconsumidores.org.co/index. php?option $=$ com_content $\&$ view $=$ sec tion\&layout $=$ blog\&id $=7 \&$ Itemid $=125$

Cronin, J., y Taylor, S. (1992). Measuring services quality: a reexamination and extension. Journal of Marketing, 56(3), 55-68.

Cubillos, R., y Rincón, E. (2002). Introducción jurídica al comercio electrónico. Colombia: Ediciones Jurídicas Gustavo Ibáñez.

Davis, H. (1976). Decision Making Within the Household. Journal of Consumer Research, 2(1), 241-260. 
Del Río, P. (1986). Publicidad y consumo: hacia un modelo educativo. Infancia y aprendizaje, 35-36, 139-173.

Dolci, M. (2007). Testimonio: la visión desde las entidades de defensa del consumidor. Nueva Sociedad, 16(1), 1-7.

Galtung, J. (1964). Foreign Policy Opinion as a Function of Social Position. Journal of Pace Research, 1(3), 206-231.

García de la Cruz, J. (1995). La defensa de intereses ante las autoridades públicas. ¿Acción colectiva o acción individual? Revista Española de Investigaciones Sociológicas, 69, 39-68.

Mandrick, C., y Bao, Y. (2005). Exploring the Concept and Measurement of General Risk Aversion. Advances in Consumer Research, 32(1), 531-539.

Navarro, R. M. (2016). ¿Consumir responsablemente es cuestión de actitud? Inpsicon, Investigación en Psicología del Consumidor. Recuperado el 5 de agosto de 2016 de http://inpsicon.com/ es/2016/04/13/estudios-sobre-actitudy-comportamiento-ecologico/

Onkvisit, S., y Shaw, J. (1987). SelfConcept and Image Congruence: Some Research and Managerial Implications. Journal of Consumer Marketing, 4(1), 13- 23.

Pascual M., y Román S. (2011). Desconfianza hacia la venta tradicional y electrónica: Un estudio sobre el perfil del consumidor desconfiado. Universia Business Review 1(1), 132-154.

Penz, G. (1986). Consumer Sovereignty and Human Interests. Cambridge: Cambridge University Press.
Ramírez, A., Navarro, C., y Trujillo, M. (2002). Consumerismo y movimiento de los consumidores: valores, actitudes y comportamiento consumerista en la población andaluza. Revista Española de Investigaciones Sociológicas, 99(2), 146-176.

Ramírez, C. (2005). ¿Y dónde está el cliente? Vender en los tiempos de crisis. Recuperado de http://www.sht.com.ar/ archivo/Management/cliente.htm

Restrepo, J. (2012). Abogacía de la Competencia: la nueva tarea de la Superintendencia de Industria y Comercio. Revista de Derecho y Economía, 36(1), 59-78.

Rodríguez, J. (2005). Aproximación teórica al modelo psico-económico del consumidor. Psicología desde el Caribe, 16(1), 92-127.

Ruíz de Maya, S., y Alonso, J. (2001). Experiencias y casos de comportamiento del consumidor. Madrid: ESIC.

Ruiz-Olalla, C. (2001). Gestión de la calidad del servicio, control de gestión. Recuperado de http://www.5campus. com/leccion/calidadserv

Serna, H. (1999). Servicio al cliente. Métodos de auditoria y medición. Colombia: Cargraphics S.A.

Suárez, G. (2001). Hacia una Defensa del Consumidor de Medios. Palabra Clave, 4, 73-78.

Thompson, J., y Tuden, A. (1959). Strategies, Structures and Processes of Organizational Decision. En J. Thompson et al. (Eds.), Comparative Studies in Administration. Pittsburg: Universidad of Pittsburg. 
Trímboli, J. (2004). Educación del consumidor: realidad y perspectiva. Decision, 8, 1-11.

Van Raaij, W. (1981). Economic Psychology. Journal of Economic Psychology, 1(1) 1-24.

Ward, S., Klees, D. M., y Robertson, T. S. (1987). Consumer Socialization in Different Settings: an International Perspective. Advances in Consumer Research, 14, 468-472.
Wellington, P. (1997). Cómo brindar un servicio integral de atención al cliente. Caracas: McGraw-Hill.

Yang, M., Chandlrees, N., Lin, B., y Chao, H. (2009). The Effect of Perceived Ethical Performance of Shopping Websites on Consumer Trust. Journal of Computer Information Systems, 50(1), 15-24. 